TABLE II-Mean Levels ( \pm S.E.) of Variables in the Two Groups

\begin{tabular}{l}
\hline \\
\hline
\end{tabular}

Differences between mean levels of $P-R$ and proportions with extrasystoles differ significantly at $P<0.05$.

\section{Discussion}

An aspect of this study which requires careful consideration is the sensitivity of the various comparisons made. This can be judged from the sizes of the standard errors (S.E.) shown in Tables I and II. These indicate that for each of the variables a difference which is smaller than that likely to be clinically important would have been detected as statistically significant at conventional levels (twice the S.E. of the difference between the two means). Thus for blood pressure differences in means of more than $3.6 \mathrm{~mm}$ systolic or $2.3 \mathrm{~mm}$ diastolic, or a difference greater than $6.5 \mathrm{mg}$ of cholesterol, would be statistically significant at $P<0.05$. All these differences, and those for the other variables, are acceptably small.

The few differences which have been detected at $\mathrm{P}<0.05$ are difficult to interpret. There is a significant difference in mean age $(2 \cdot 1$ years $)$ but this is very small and unlikely to be important in the overall comparisons presented. In any case the data were analysed within three age groups separately and the conclusions which follow are based on this more detailed examination. The significant difference in mean P-R duration is of interest as it is consistent within the three age groups, but its clinical importance is unknown. The increased proportion of men with extrasystoles of ventricular origin in hard water areas is statistically significant but is not consistent in direction within the three age groups examined. A measurement based on a short E.C.G. run is unlikely to be reliable either for an individual or for a group, but, nevertheless, the presence of ventricular extrasystoles in a routine E.C.G. has been shown to indicate an increased mortality risk (Chiang, Perlman, Ostrander, and Epstein, 1969). The higher prevalence of angina in the hard water area, though not significant, is also of interest, as it is inconsistent with a lower mortality in these areas. However, hardness of water appears to be relevant to the process of infarction rather than to the development of arteriosclerosis (Crawford and Crawford, 1967). The Q-T interval in the two groups is identical, even when examined as a regression on $R-R$. This is of interest, as a prolongation of this interval is associated with sudden death (James, 1969).

It is perhaps more important, however, to stress the absence in these data of differences in most variables which are statistically or clinically important. While they cannot rule out, with absolute certainty, any of the possible mechanisms by which water affects mortality, they do indicate areas into which future investigations may most profitably be directed.

\section{References \\ ${ }^{1}$ Begg, T. B., Wade, I. M., and Bronte-Stewart, B. (1966). Fournal of Atherosclerosis Research, 6, 303. \\ Chiang, B. N., Perlman, L. V., Ostrander, L. D., jun., and Epstein, F. H. (1969). Annals of Internal Medicine, 70, 1159. \\ ${ }^{3}$ Crawford, M. D., Gardner, M. J., and Morris, J. N. (1968). Lancet, $1,827$. \\ - Crawford, T., and Crawford, M. D. (1967). Lancet, 1, 229. \\ 5 Davies, D. F. (1958). Clinical Science, 17, 563. \\ - Hart, J. T. (1970). Fournal of the Royal College of General Practitioners, $19,258$. \\ 7 James, T. N. (1969). Modern Concepts of Cardiovascular Disease, 38, 35. \\ Khosla, T., and Lowe, C. R. (1967). British fournal of Preventive and Social Medicine, 21, 122 \\ 9 Kobayashi, J. (1957). Bericht des Ohara Instituts für landwirtschaftliche Biologie, 11, 12 . \\ ${ }^{10}$ Rose, G. A. (1962). Bulletin of the World Health Organization, 27, 645. \\ 11 Schroeder, H. (1960). Fournal of the American Medical Association, $172,1902$.}

Medical Research Council, London W1N 4AL

RODNEY SWEETNAM, F.R.C.S., Orthopaedic Surgeon, Middlesex Hospital, London W.1

JOHN KNOWELDEN, M.D., M.R.C.P., Professor of Preventive Medicine and Public Health, University of Sheffield

SIR HERBERT SEDDON, C.M.G., D.M., F.R.C.s., Honorary Consultant Surgeon, Royal National Orthopaedic Hospital, London W IN 6AD prospective study. Of the 192 patients available for the comparison, those treated by radiotherapy alone did least well. A combination of the two treatmentsradiotherapy followed by amputation-produced better results, in terms of survival, than amputation alone; however, the comparatively small numbers involved and the inadequacy of information about the factors dictating the choice of treatment make firm conclusions impossible. A controlled clinical trial on a larger scale might provide answers to the outstanding questions.

\section{Introduction}

The efficacy of any form of treatment of osteosarcoma has always been low, and the rarity of the disease has hindered the collection of sufficient information on which to base an evaluation of the respective merits of surgery, radiotherapy, and a combination of the two forms of treatment. The M.R.C. 
Working Party on Bone Sarcoma* was therefore set up with the aim of remedying this situation. It was also evident that a retrospective study of osteosarcoma would be necessary before plans for a prospective one could be considered. This survey is the subject of the present report.

\section{Patients and Methods}

The study was initially confined to the Middlesex, Westminster, Royal Marsden, Mount Vernon, and Royal National Orthopaedic Hospitals, but it later proved necessary to extend it to nearly all the major centres in the United Kingdom. $f$ It was decided to confine the study to patients treated after the introduction of supervoltage radiotherapy in 1951; all records of primary malignant tumours of the femur and tibia were therefore examined for the period 1952-9 inclusive. The limitation with regard to the site of the tumour was designed to facilitate comparison between the various treatment groups.

Mr. D. R. Sweetnam was responsible for assembling the material at the Institute of Clinical Research of the Middlesex Hospital. Some of the participating centres lent their records, while others had to be visited; relevant data were extracted from the case notes and $x$-ray films were copied. All information was recorded on a special form designed by the Working Party. Histological material was reviewed by the Bone Tumour Pin=l of the British Empire Cancer Campaign, $\ddagger$ a group of pathologists with special experience in the diagnosis of bone tumours. Only histologically authenticated cases of osteosarcoma were included in the final group of patients analysed. We are grateful to the members of this panel, not only for their painstaking work but because without their expert knowledge the survey would not have been possible. The organization of a panel of radiologists to examine the $x$-ray films proved impracticable, and Dr. Campbell Golding undertook the responsibility of reviewing the copies.

Of the 469 patients studied, 201 were considered by the panel of pathologists to have histologically proved osteosarcoma. Sixteen of these had originally been diagnosed as suffering from some other form of tumour. The panel rejected an original diagnosis of osteosarcoma in 13 cases, and in 55 others it was unable to give a more precise designation than "primary malignant tumour of bone, unspecified." In 13 of these 55 cases the original diagnosis had been osteosarcoma and the radiological appearances in about half of them were consistent with this finding. In only one patient with histologically confirmed osteosarcoma, among those whose $x$-ray films were of sufficiently good quality for accurate assessment, was the diagnosis disputed on radiological grounds. In three the appearance was compatible with a diagnosis of osteosarcoma, but this was not the first choice. In the remainder osteosarcoma was the first choice.

*The members of the Working Party were: Sir Herbert Seddon (chairman), Professor Sir John Bruce, Sir Stanford Cade, Dr F. Campbell Golding, Professor Sir Austin Bradford Hill, Professor J. Knowelden, the late Professor R. W. Scarf, Professor E. F. Scowen, Professor Sir Brian Windeyer, and Mr. Rodney Sweetnam (secretary).

tList of centres, Bone Sarcoma Survey: Heatherwood Hospital, Ascot; the United Birmingham Hospitals; Bristol Bone Tumour Registry; the United United Birmingham Hospitais; Bristol Bone Tumour Registry; the United Cambridge Hospitals; the Royal Infirmary, Prince of Wales Orthopaedic Hospital, and South Wales Radiotherapy Centre, Cardiff; Dundee Royal Infirmary; Royal Infirmary and Western General Hospital, Edinburgh; Princess Elizabeth Orthopaedic Hospital, Exeter; Western Infirmary, Glasgow, and Scottish Bone Tumour Registry; St. James's Hospital, Leeds; the United I.iverpool Hospitals; Charing Cross Hospital, Great Ormond Street Hospital for Sick Children, Guy's Hospital, King's College Hospital ; the London Hospital, the Middlesex Hospital, Mount Vernon Hospital, Royal Free Hospital, Royal Marsden Hospital, Royal National Orthopaedic Hospital, St. Bartholomew's Hospital, St. George's Hospital, St. Mary's Hospital, St. Thomas's Hospital, University College Hospital, and Westminster Hospital, London; Manchester Royal Infirmary; the United Newcastle upon Tyne Hospitals; Norfolk and Norwich Hospital; the Robert Jones and Agnes Hunt Orthopaedic Hospital, Oswestry; the United Oxford Hospitals; the United Sheffield Hospitals. $\ddagger$ The members of the panel were: the late Professor R. W. Scarff (chairman),
Dr. J. Ball, Dr. P. D. Byers, Dr. Mary Catto, the late Dr. W. Goldie, Dr. C. H. G. Price, and Dr. H. A. Sissons (secretary).
Of the 201 patients with osteosarcoma four were given palliative treatment only and three none at all; two more had to be excluded from any comparison of the three main types of treatment because only local excision had been performed. There thus remained 192 patients in all for further consideration.

With this procedure, designed to include all cases from each centre, there was no bias in the selection of the material. The clinical details were often incomplete. Progress was not always reported, and failure to record a patient's destination on discharge made it difficult to trace him as he was transferred from one hospital to another-perhaps from a small hospital where he was first examined to a larger unit for biopsy and then to a radiotherapy centre. It was also often impossible to discover why a particular course of action had been taken: the reasons for deciding on, say, amputation after radiotherapy or for the length of the interval between these two procedures had not been recorded. It seemed that the choice depended mainly on the policy of the centre concerned, all patients referred to it tending to be given similar treatment.

\section{Findings}

Of the 192 patients $62 \%$ were male and $38^{\circ} \%$ female, a ratio of 1.6 to 1 (Table I). In 125 patients the site of the sarcoma was the femur (the lower end in 111 cases) and in 67 the tibia (the upper end in 56). Thus $83 \%$ of tumours occurred around the knee joint. The distribution in relation to age followed the typical pattern, except that there were fewer older patients than might be expected with ostcosarcoma in association with Paget's disease. Nevertheless, as expected, this combination was found in most of the small group of 11 patients aged 60 years and over, nine of whom had Paget's disease. The average duration of symptoms before treatment began was three months; among those who survived, it was four months. Pain alone was the presenting symptom in $63 \%$ of patients, swelling alone in $16 \%$, and both simultaneously in $20 \%$; thus pain was a presenting symptom in $83 \%$ altogether. Only $12 \%$ of patients gave a history of injury, and none of fractures. Sun-ray spicules, said to be a characteristic radiographic feature, were present in only $16 \%$ of cases.

Eighty patients $(42 \%)$ were treated by a combination of radiotherapy and amputation, $61(32 \%)$ by amputation alone, and $51(27 \%)$ by radiotherapy. In the first group, two were irradiated before and after amputation and the rest only before amputation. The interval between completion of irradiation and amputation varied greatly. There were considerable variations in the duration and dosage of radiotherapy.

\section{SURVIVAL}

Table I shows the number of patients and the proportion surviving five years from the start of treatment, subdivided by age, sex, and site of tumour. Overall, $22^{\circ}$ of the patients survived at least five years. There were no appreciable differences from this rate for men or women, nor for patients with tibial or femoral tumours. There were no five-year survivors among

TABle I-Numbcr of Patients and Proportion surviving Five Years according to Age, Sex, and Site

\begin{tabular}{|c|c|c|c|c|c|c|}
\hline \multirow{2}{*}{\multicolumn{4}{|c|}{ Group }} & \multirow{2}{*}{$\begin{array}{l}\text { No. of } \\
\text { Patients }\end{array}$} & \multicolumn{2}{|c|}{ Five-year Survivors } \\
\hline & & & & & No. & $"$ \\
\hline \multicolumn{3}{|c|}{$\begin{array}{l}\text { All Groups } \\
\text { Age in } \\
\text { years }\end{array}\left\{\begin{array}{l}\text { Under } 20 \\
20-39 \\
40-59\end{array}\right.$} & $\begin{array}{l}\ldots \\
\cdots \\
\cdots\end{array}$ & $\begin{array}{r}192 \\
136 \\
30 \\
15 \\
11\end{array}$ & $\begin{array}{r}42 \\
29 \\
9 \\
4 \\
0\end{array}$ & $\left.\begin{array}{r}21.9 \\
21.3 \\
30.0 \\
26.7 \\
0.0\end{array}\right\}(0.3<P<0.5)$ \\
\hline Sex & $\left\{\begin{array}{l}\text { Male } \\
\text { Female }\end{array}\right.$ & $\begin{array}{l}\cdots \\
\cdots\end{array}$ & $\begin{array}{l}\ldots \\
\ldots\end{array}$ & $\begin{array}{r}120 \\
72\end{array}$ & $\begin{array}{l}29 \\
13\end{array}$ & $\left.\begin{array}{l}24.2 \\
18.1\end{array}\right\}(0.3<P<0.5)$ \\
\hline Site & $\left\{\begin{array}{l}\text { Tibia } \\
\text { Femur }\end{array}\right.$ & 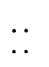 & $\because$ & $\begin{array}{r}67 \\
125\end{array}$ & $\begin{array}{l}13 \\
29\end{array}$ & $\left.\begin{array}{l}19.4 \\
23.2\end{array}\right\}(0.5<P<0.7)$ \\
\hline
\end{tabular}


those aged 60 and over, but this was a small group of only 11 patients, and the younger groups showed little contrast. None of the differences in Table I were significant.

The proportion surviving five years is a relatively uninformative measure, and Table II and Fig. 1 show the pattern in greater detail. It is clear that mortality was concentrated in the

TABLE II-Proportion of Patients Surviving Specified Intcrvals from Start of Treatment and Median Survival Time, by Age

\begin{tabular}{|c|c|c|c|c|c|c|}
\hline \multicolumn{3}{|c|}{$\begin{array}{l}\text { Interval } \\
\text { (Months) }\end{array}$} & \multirow{2}{*}{$\begin{array}{c}\begin{array}{c}\text { Under } 20 \text { Years } \\
\text { (136 Patients) } \\
(" .,)\end{array} \\
100 \\
88 \\
57 \\
31 \\
24 \\
21 \\
21\end{array}$} & \multirow{2}{*}{$\begin{array}{c}\begin{array}{c}20-59 \text { Years } \\
\text { (45 Patients) } \\
\left.\left({ }^{\circ}\right)_{0}\right)\end{array} \\
100 \\
96 \\
71 \\
49 \\
38 \\
31 \\
29\end{array}$} & \multirow{2}{*}{$\begin{array}{c}60 \text { Years and Over } \\
\text { (11 Patients) } \\
\text { ("o) }\end{array}$} & \multirow{2}{*}{$\begin{array}{c}\begin{array}{c}\text { All Ages } \\
\text { (192 Patients) } \\
\text { (") })\end{array} \\
100 \\
87 \\
58 \\
34 \\
26 \\
22 \\
22\end{array}$} \\
\hline $\begin{array}{r}0 \\
6 \\
12 \\
24 \\
36 \\
48 \\
60\end{array}$ & $\begin{array}{l}\ldots \\
\cdots \\
\cdots \\
\cdots \\
\cdots \\
\cdots\end{array}$ & $\begin{array}{l}\ldots \\
\cdots \\
\cdots \\
\cdots \\
\cdots \\
\cdots\end{array}$ & & & & \\
\hline \multicolumn{3}{|c|}{$\begin{array}{c}\text { Median survival } \\
\text { (months) .. }\end{array}$} & $15 \cdot 1$ & $23 \cdot 4$ & 5.5 & $16 \cdot 1$ \\
\hline
\end{tabular}

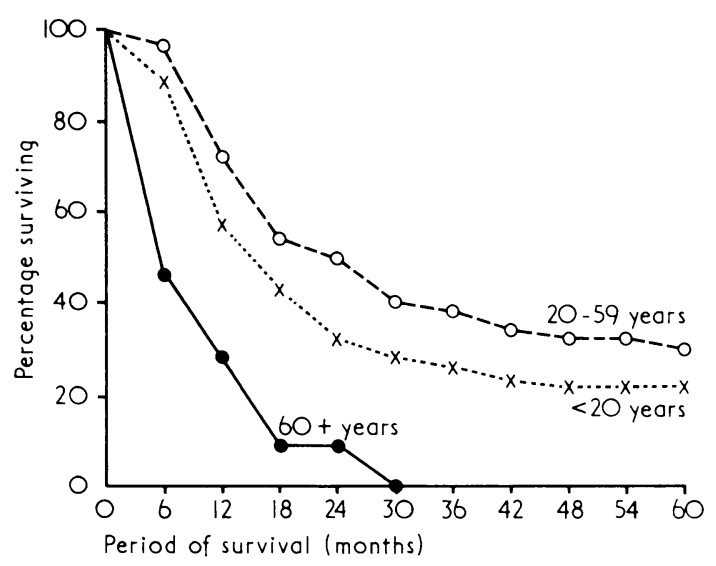

IFI. 1-Pcriod of survival according to age group.

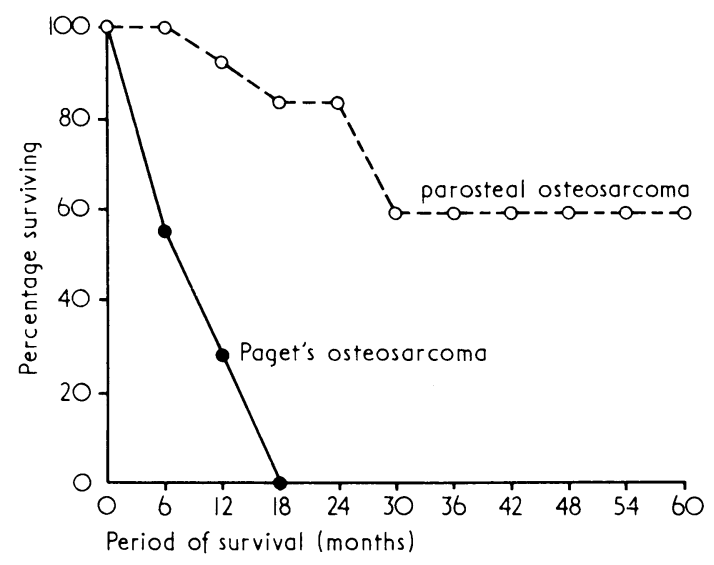

FIG. 2-Parosteal and Paget's osteosarcoma.

first two years from starting treatment, nearly all in patients aged 60 and over, and that thereafter the survival curve flattened out. The median survival time was $16 \cdot 1$ months for all patients and $15 \cdot 1$ months for the largest group of patients, those under 20 years.

The more favourable prognosis for parosteal tumours (12 cases) and the fatality of Paget's osteosarcoma are shown in Fig. 2. Exclusion of the patients with these tumours from the three treatment groups made a difference of only 0.3 to the percentage of survivors. The survival period did not vary according to whether the tumour was predominantly osteolytic or osteosclerotic. Nor did pathological fractures, which occurred in $10 \%$ of cases, affect the prognosis. The chances of survival were somewhat better if a tumour was very small, particularly in patients treated by amputation alone. There was no correlation between tumour size and length of history.

Pulmonary metastases developed within 10 months, on average, of starting treatment, and the average period between the discovery of pulmonary metastases and death was six months. Resection of a solitary metastasis was carried out in only three patients; one died six months after lobectomy, at which hilar glands were found to be involved, and the other two were alive four and a half and seven years afterwards with no evidence of recurrence.

Lymph node metastases were found in $3{ }^{\prime} \%$ of those who died; but necropsies were performed in barely $10 \%$ of the cases in this series, and the records seldom indicated whether a search was made for such metastases either at necropsy or at amputation.

Table III presents a comparison of five-year survival between the treatment groups. Taking all ages together, the proportion

TABle III-Proportion of Patients Survizing Five Years, by Method of Treatment and Age

\begin{tabular}{|c|c|c|c|c|c|c|c|c|}
\hline \multirow{2}{*}{$\begin{array}{l}\text { Treatment } \\
\text { Group }\end{array}$} & \multicolumn{2}{|c|}{$<20$ Years } & \multicolumn{2}{|c|}{ 20-59 Years } & \multicolumn{2}{|c|}{$>60$ Years } & \multicolumn{2}{|c|}{ All Ages } \\
\hline & No. & $" \because$ & No. & $" 0$ & No. & ${ }_{0}^{\prime}$ & No. & $\%$ \\
\hline $\begin{array}{ll}\text { Radiotherapy } & . \\
\text { Amputation } & \ldots \\
\text { Both } \ldots & \ldots\end{array}$ & \begin{tabular}{|c|}
42 \\
40 \\
54 \\
$0 \cdot 001$
\end{tabular} & $\begin{array}{c}7.1 \\
25.0 \\
29.6 \\
P<0.01\end{array}$ & $\begin{array}{c}8 \\
14 \\
23 \\
0.5<\end{array}$ & $\begin{array}{c}37.5 \\
28 \cdot 6 \\
26 \cdot 1 \\
P<0 \cdot 71\end{array}$ & $\begin{array}{l}1 \\
7 \\
3\end{array}$ & $\begin{array}{l}0 \cdot 0 \\
0 \cdot 0 \\
0 \cdot 0\end{array}$ & $\begin{array}{c}51 \\
61 \\
80 \\
0.02\end{array}$ & $\begin{array}{c}11.8 \\
23.0 \\
27.5 \\
P<0.05\end{array}$ \\
\hline
\end{tabular}

No. = Number treated. $"{ }_{0}=$ Percentage surviving.

surviving of those treated by radiotherapy alone $\left(11 \cdot 8^{\prime \prime}{ }_{0}\right)$ was only half that for patients treated by amputation alone $\left(23^{\circ}{ }_{0}\right)$ or by both methods in combination $\left(27 \cdot 5^{\circ}{ }_{0}\right)$. The contrast was even greater for those under 20 years of age, but little difference emerged in older patients.

Table IV and Fig. 3, which are analogous to Table II and Fig. 1, show the proportions in each treatment group surviving to specified intervals from the start of treatment. Though the radiotherapy group showed a consistently poorer survival rate than the amputation group and the group treated by both

TABLE IV-Proportion of Paticnts Surviving Specificd Intervals from Stait of Treatment and Median Survival Time, by Method of Treatment

\begin{tabular}{|c|c|c|c|c|}
\hline \multicolumn{2}{|r|}{$\begin{array}{l}\text { Interval } \\
\text { (Months) }\end{array}$} & $\begin{array}{c}\begin{array}{c}\text { Radiotherapy } \\
\text { (51 Patients) } \\
\text { ("1.) }\end{array} \\
100\end{array}$ & $\begin{array}{c}\begin{array}{c}\text { Amputation } \\
\text { (61 Patients) } \\
\left({ }^{\circ}{ }_{0}\right)\end{array} \\
100\end{array}$ & $\begin{array}{c}\begin{array}{c}\text { Both } \\
(80 \text { Patients } \\
(", .1)\end{array} \\
100\end{array}$ \\
\hline $\begin{array}{r}0 \\
6 \\
12 \\
24 \\
36 \\
48 \\
60\end{array}$ & $\begin{array}{l}\cdots \\
\cdots \\
\cdots \\
\cdots \\
\cdots\end{array}$ & $\begin{array}{r}100 \\
82 \\
51 \\
20 \\
16 \\
12 \\
12\end{array}$ & $\begin{array}{r}100 \\
87 \\
57 \\
38 \\
25 \\
23 \\
23\end{array}$ & $\begin{array}{r}100 \\
90 \\
64 \\
40 \\
34 \\
29 \\
28\end{array}$ \\
\hline \multicolumn{2}{|c|}{$\underset{\text { (months) }}{\text { Median survival }}$} & $12 \cdot 4$ & 16.5 & 18.9 \\
\hline
\end{tabular}

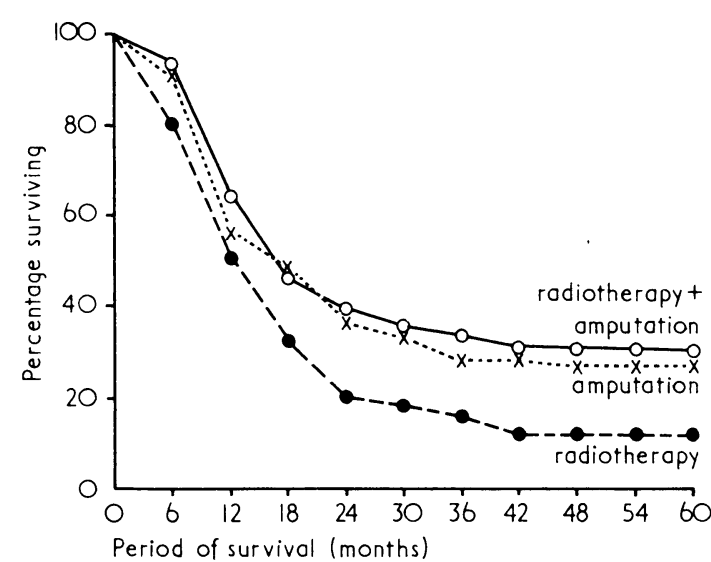

FIG. 3-Survival by method of treatment (under 20 years age group). 
methods, the differences were small and not significant at sixmonth and 12-month intervals; only from 24 months onwards did the proportion surviving among those treated by radiotherapy alone appear significantly lower. Median survival periods were 12.4 months for radiotherapy, 16.5 months for amputation, and 18.9 months for both methods.

The percentage of survivors according to the interval between radiotherapy and amputation among the 80 patients treated by both methods is given in Table V; it will be seen that where

TABLE v-Number of Patients and Proportion Surviving Five Years, by Interval between Radiotherapy and Amputation

\begin{tabular}{|c|c|c|c|c|c|}
\hline \multirow{2}{*}{\multicolumn{3}{|c|}{ Interval }} & \multirow{2}{*}{$\begin{array}{l}\text { No. of } \\
\text { Patients }\end{array}$} & \multicolumn{2}{|c|}{ Five-year Survivors } \\
\hline & & & & No. & $\%$ \\
\hline $\begin{array}{l}1-4 \text { weeks } \\
2-5 \text { months } \\
6 \text { months and over } \\
\text { Not known }\end{array}$ & $\begin{array}{l}. \\
\therefore \\
\therefore\end{array}$ & $\begin{array}{l}\ldots \\
\cdots \\
\cdots\end{array}$ & $\begin{array}{r}41 \\
19 \\
19 \\
1\end{array}$ & $\begin{array}{l}6 \\
6 \\
9 \\
1\end{array}$ & $\begin{array}{c}14 \cdot 6 \\
31 \cdot 6 \\
47 \cdot 4 \\
-\end{array}$ \\
\hline \multicolumn{3}{|c|}{ Total } & 80 & 22 & $27.5(0.01<P<0.02)$ \\
\hline
\end{tabular}

amputation was delayed the proportion of survivors was higher. A study of differences in the radiotherapy regimens did not show any clear pattern of success or failure.

\section{BIOPSY}

Twenty-nine patients were given radiotherapy (to a total dose of the order of 1,000 rads) before biposy. This did not affect the prognosis; the proportion of survivors $(6=20 \cdot 7 \%$ ) was similar to that for the series as a whole. Nor did delay in starting treatment after biopsy apparently affect the outcome; this finding is of doubtful significance, however, in view of the lack of information on the reasons for delay. It had been hoped that the survey would show whether the theoretical advantage of drill biopsy-minimal tissue disturbance and hence less risk of tumour dissemination-made it superior to open biopsy. Unfortunately drill biopsy was performed on only six patients, compared with 169 who had open biopsy. The fact that only two of the 15 patients who had no biopsy survived does, however, suggest that there is no overwhelming advantage in avoiding biopsy altogether, and therefore implies that the drill method is no safer than open biopsy.

\section{Discussion}

This study has emphasized once again that even when they are treated in the major centres the prognosis for bone sarcoma patients is poor. For patients aged 60 and over treatment can be only palliative; none of the 11 patients in this series survived more than three years (Table II and Fig. 1). For this Paget's sarcoma was chiefly to blame. In the other small group of 12 patients with parosteal growths the prognosis was much better (Fig. 2), but for the largest group, the 136 patients under 20 years, only $22 \%$ survived five years.

For the patients under 20 years of age $(70 \%$ of the total) the survival rate of the group treated by radiotherapy was less than that of the group treated by amputation or of the group treated by a combination of radiotherapy and amputation (Table III and Fig. 3); among the much smaller number of older patients there were no significant differences in survival between the treatment groups. Despite the apparent failure of radiotherapy alone, it is impossible to draw any conclusion about the relative merits of these treatments without knowing why the particular form of treatment was chosen for each patient, and this information was very rarely available in the case notes. The demonstration that survival rate was better when the interval between radiotherapy and amputation was longer (Table $\mathrm{V}$ ) illustrates the difficulty; one explanation of this finding could be that the patients who had the operation six or more months after radiotherapy had already demonstrated their ability to survive a period which had seen the death of the more serious casesthat is, they were a selected group of patients with a better prognosis irrespective of treatment. Furthermore, we do not know how many patients were intended to have combined treatment, but were given radiotherapy alone because pulmonary metastases had developed early before amputation could be performed; neither do we know how often it was hoped that radiotherapy alone would suffice, but the failure of response or local recurrence necessitated surgery in addition.

A comparison can be made between all those patients treated by radiotherapy (whether or not there was a subesquent amputation) and those treated by amputation alone. This is shown in Table VI; in each age group the proportion surviving five years was very similar; in the main group (under 20 years of age) the five-year survival rate for patients treated by amputation alone $(25 \%)$ was marginally better than that for all patients receiving radiotherapy $(19.8 \%)$, and at other ages the proportions were even closer. Thus these figures give no support, in terms of survival rates, to a preference for treatment by prinary amputation alone.

This type of survey is far removed from a clinical trial in which patients are allocated to the various treatment groups at random. Clinicians may be reluctant to co-operate in such a trial, but even if they were persuaded to do so, there would be considerable difficulty in obtaining a valid assessment of the relative merits, measured by survival, of the three treatment methods. Table II shows that the contrasts were irregular, with different patterns for those under 20 and those 20-59 years of age, and the differences between the groups treated by amputation alone and by both radiotherapy and amputation in combination were small and nowhere near statistical significance. It would seem, therefore, that a very long series would be required to establish a clear and consistent pattern. It can be estimated from the data of Mackenzie et al. (1961) that annually only about 40 patients under 60 with osteosarcoma of the femur or tibia would be available for follow-up in the whole of the United Kingdom. Clearly, nothing less than a national study admitting patients for many years would suffice for a prospective comparison of treatments. There is always the possibility that some more promising line of treatment, resulting perhaps from advances in immunology or chemotherapy, might emerge before it was complete. It has seriously to be considered whether any progress is possible until some new and more promising treatment is discovered.

This study does not touch on the effect of different methods of treatment on the comfort of the patient. This may well be the

TABLE VI-Comparison of Survival between All Patients Treated by Radiotherapy and Those Treated by Amputation Alone

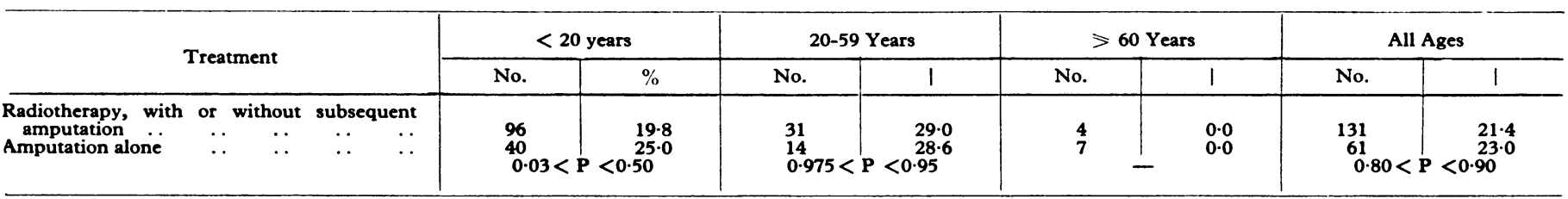

No. $=$ Number treated. $\%=$ Percentage surviving. 
most important aspect for most patients, who in the present situation cannot expect to survive more than a few years and who may suffer the anguish of local recurrence before death.

The Working Party wishes to pay tribute to the generosity of the Nathan Trust, which provided considerable financial assistance. It is grateful to the Bone Tumour Panel of the British Empire Cancer Campaign for reviewing the histological material and to the department of morbid anatomy of the Institute of Orthopaedics (Dr. H. A.
Sissons) for preparing the many histological sections concerned and arranging their circulation to the panel. Furthermore, the Working Party is deeply appreciative of the generous co-operation of the clinicians and pathologists in the centres which supplied information.

\section{Reference}

Mackenzie, A., Court Brown, W. M., Doll, R., and Sissons, H. A. (1961). British Medical fournal, $1,1782$.

\title{
Oestrogen as a Reticuloendothelial Stimulant in Patients with Cancer
}

\author{
C. J. MAGAREY, M. BAUM
}

British Medical fournal, 1971, 2, 367-370

\section{Summary}

Stimulation of reticuloendothelial activity may benefit patients with cancer. Oestrogenic compounds are known to stimulate reticuloendothelial phagocytic activity in animals and a similar effect is demonstrated in patients.

The depression of reticuloendothelial phagocytic activity which follows radiotheraphy in the treatment of cancer can be prevented by the simultaneous administration of stilboestrol. Possibly this could be associated with a more favourable response to therapy, and a controlled trial is needed to establish this.

\section{Introduction}

The reticuloendothelial system is important in the natural resistance of cancer patients to the spread of their tumours (Green et al., 1967). Phagocytic activity in particular has been found to reflect this resistance (Magarey and Baum, 1970). But this activity is depressed by ionizing radiation or cytotoxic drugs used in the treatment of patients with cancer (Magarey and Baum, 1970). In animals the spread of tumours is increased by agents which depress reticuloendothelial phagocytic activity (Kondo and Moor, 1961; Reiner and Southam, 1966; Dao and Yogo, 1967; Rosenau and Moon, 1967). Conversely, agents which stimulate reticuloendothelial phagocytic activity reduce the spread of these tumours (Bradner and Clarke, 1959; Old et al., 1961; Yamaguchi et al., 1965; Halpern et al., 1966; Woodruff and Boak, 1966). Such reticuloendothelial stimulants potentiate the antitumour effects of cytotoxic compounds (Sokoloff et al., 1961; Martin et al., 1964). So far, there have been few serious attempts to stimulate reticuloendothelial activity in humans with cancer, though Mathé (1969) claimed some success with B.C.G. in patients with leukaemia.

Oestrogens are potent stimulants of reticuloendothelial phagocytic activity in laboratory animals (Nicol, 1935; Biozzi et al., 1957; Nicol et al., 1964). They. like other reticuloendothelial stimulants, give some protection against the toxic effects of $x$-irradiation (Treadwell et al., 1943; Mirand and Lasser,

\footnotetext{
Department of Surgery, King's College Hospital Medical School, London S.E.5

C. J. MAGAREY, F.R.C.S., F.R.C.S.ED., Research Fellow (Present appointment: Surgical Registrar, Royal United Hospital, Bath)

M. BAUM, F.R.C.S., Lecturer
}

1955) and cytotoxic compounds (Baum, 1967; Field et al., 1967). Oestrogens have been used for years in the treatment of patients with breast or prostatic cancer, but their mode of action is not fully understood. Nicol et al. (1952) provided histological evidence that macrophage activity may be involved in the response of prostatic cancer to oestrogens, but there have been few experimental studies of the effects of oestrogen on the host response to tumour. There have been no such studies in man, though oestrogens are less toxic than the reticuloendothelial stimulants which have so far been considered for use in patients with cancer.

The following investigations were undertaken to study the effects of several oestrogens on the reticuloendothelial phagocytic activity in patients with cancer and in patients without malignant disease and, in addition, the effect of combining stilboestrol with radiotherapy in the treatment of patients with cancer.

\section{Patients and Methods}

Sixty-three patients volunteered for this study (Table $\mathrm{I}$ ). Fifteen who had malignant disease and 33 who had no malignant disease, all of whom were in good general health, were given oestrogen. Another seven patients received stilboestrol while undergoing radiotherapy. These patients received no other specific treatment during the investigation except promethazine or perphenazine to prevent the nausea sometimes produced by oestrogen. The other eight patients without malignant disease acted as controls and took promethazine or perphenazine but no oestrogen. The results obtained in the patients undergoing radiotherapy have been compared with those obtained in 22 patients receiving similar radiotherapy without stilboestrol (Magarey and Baum, 1970).

The oestrogens were taken orally. Stilboestrol was taken in three dose ranges $(1 \mathrm{mg}$ three times daily, 5-10 $\mathrm{mg}$ three times daily, or $25 \mathrm{mg}$ four times daily). Ethinyloestradiol was taken in two dosages $(0.1$ or $1 \mathrm{mg}$ three times daily). Oestriol was

TABLE I-Patients in Study

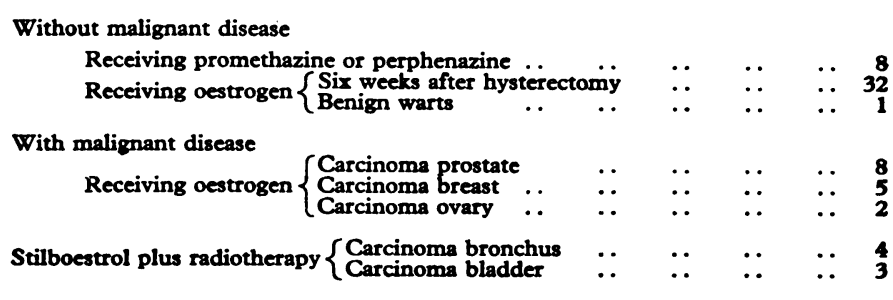

